AAC 7, 1996, pp. 9-32

\title{
ALGUNAS REFLEXIONES SOBRE LA FASE ANTIGUA DE LA CONTESTANIA IBÉRICA: DE LA TRADICIÓN ORIENTALIZANTE AL PERÍODO CLÁSICO
}

\author{
Feliciana SALA SELLÉS \\ Universidad de Alicante
}

\section{Resumen}

En este trabajo se tratan una serie de rasgos que están empezando a caracterizar la fase ibérica antigua de la Contestania. Se hace hincapié asimismo en aquellos hechos que dejan entrever la estrecha relación cultural de este momento con el período anterior. La novedad de la documentación impide presentarlos con carácter definitivo, pero sí nos permite entenderlos como puntos de partida de futuras investigaciones.

\section{Résumé}

Dans cet article on analyse une série de faits qui commencent à caracteriser la fase ibérique antique de la Contestania. On insiste surtout sur ceux qui laissent entrevoir l'étroite relation culturelle de cette époque avec l'anterieure. La recente découverte de l'information empêche de les présenter avec un caractère definitif, mais par contre elle nous permet de les apprehendre comme point de départ de futures recherches.

\section{LA HERENCIA DE LA HISTORIOGRAFÍA}

Hasta hace apenas dos décadas nadie podía imaginar la existencia de un estadio antiguo en la evolución de la Cultura Ibérica. La imagen del mundo ibérico como manifestación bastante tardía, a lo sumo contemporánea en sus inicios de la cerámica griega de figuras, había nacido plenamente aceptada y fue pareja a los avances de la propia investigación. No podía ser de otro modo ya que las excavaciones de principios de siglo en el Sureste sacaban a la luz una vistosa cerámica figurada, cuya importancia manifiesta y su relación con vasos romanos de terra sigillata relegaban al 
olvido aquellos otros con decoración geométrica que desde fines del siglo XIX estaban apareciendo en el valle del Guadalquivir y tenían visos de ser bastante antiguos; en el otro extremo, las excavaciones en Ampurias mostrando a la investigación que en las capas más profundas de la sucesión estratigráfica la cerámica ibérica geométrica se encontraba junto con vasos áticos de barniz negro y de figuras rojas (CAZURRO y GANDÍA, 1913-14).

Esta idea, extendida como principio general a todos los territorios ibéricos, hizo en el caso de la Contestania que en las obras de S. Nordström (1973) o E. Llobregat (1972) se propusiera la segunda mitad del s. V aC como fecha más alta para los orígenes ibéricos. Afortunadamente, en aquellas fechas empezaba a descubrirse un contexto cultural protohistórico que finalmente ha permitido ubicar la Cultura Ibérica en la continuidad histórica de la Península. En efecto, las excavaciones en los asentamientos coloniales instalados en el litoral peninsular demostraban la existencia de una cerímica a torno muy antigua -más incluso que las primeras ibéricas-, que formaba parte del ajuar de unas viviendas de planta rectangular construidas técnicamente como las de los poblados ibéricos. Así es como la investigación ha podido rellenar el "Vacío» entre el final de la Edad del Bronce y la Cultura Ibérica clásica con un período en el que convergen las innovaciones traidas por los pueblos mediterráneos y su asimilación por parte de los pueblos indígenas. Hoy nadie duda que en ello reside el origen de la Cultura Ibérica.

En la región contestana, se ha podido analizar este proceso gracias a los trabajos en dos yacimientos protohistóricos claves: en Los Saladares (Orihuela) (ARTEAGA y SERNA, 1975) primero, y en Peña Negra (Crevillente) después (GONZÁLEZ PRATS, 1983); a principios de los 80, los descubrimientos en estos poblados sumados a otros del País Valenciano (Los Villares, Vinarragell, Puig de la Nau, Puig de la Misericordia) indicaban el carácter generalizado del proceso en todo el Levante. En el territorio que nos interesa, la Vega Baja del río Segura, quedaba resuelta la presencia de comerciantes fenicios en Peña Negra' y con ellos las condiciones que darían origen al mundo ibérico; pero este enclave se abandonaba a mediados del s. VI aC, Saladares parecía continuar hasta época ibérica plena aunque de una manera confusa, y los poblados ibéricos ya conocidos en la comarca no se fechaban más allá de fines del $\mathrm{s} . \mathrm{V}$ aC: seguía existiendo, por tanto, un período de más de un siglo inexplicablemente vacío. Por suerte, en aquellos momentos se iniciaban las excavaciones en un poblado ibérico situado en la misma comarca, El Oral, cuya fundación se podía establecer en los postreros años del s. VI aC y su final en torno a la mitad de s. $\mathrm{V}$ aC; con esta cronología constituía el enlace entre el poblamiento orientalizante y los poblados ibéricos clásicos de la zona (ABAD, 1987, 158-161).

Hoy confirmada por la existencia de fa factoría fenicia bajo las ruinas del Ribat califal en las dunas de Guar- 


\section{EL CARÁCTER DE LA DOCUMENTACIÓN}

Teníamos ya la fase ibérica antigua perfilada y los elementos materiales para analizarla. En el resto del País Valenciano también se estaban produciendo descubrimientos en esta misma línea: se detectan niveles ibéricos antiguos en el Abric de Les Cinc (Almenara, Castellón) (JUNYENT et alii, 1982-83); se inician excavaciones sistemáticas en los poblados del Puig de la Misericordia (Vinaroz) y Puig de la Nau (Benicarló) (GUSI y OLIVER, 1987); y se reanudan en Los Villares (Caudete de las Fuentes, Valencia) (MATA, 1991). Poco a poco se va dando contenido a un poblamiento del que hasta entonces sólo se conocían sus aspectos funerarios a través de necrópolis como La Solivella (Alcalá de Chivert, Castellón) y El Molar (Guardamar, Alicante) principalmente. En la región contestana, el escaso número de yacimientos ibéricos antiguos conocidos y la fragmentaria información que se tenía de ellos había impedido construir una idea de conjunto. Hoy contamos con cuatro yacimientos cuya información disponible puede sernos de utilidad en un estudio como el que nos proponemos.

La necrópolis de El Molar (Guardamar) es la primera necrópolis de esta cronología que se conoce en el País Valenciano. Su excavación tuvo lugar en 1928 y 1930 en sendas campañas dirigidas respectivamente por J. Lafuente y J. Senent, al que se debe la Memoria final de las excavaciones (SENENT, 1930). Nordström realizó el primer estudio del yacimiento, determinando su cronología entre el 450 y el $350 \mathrm{aC}$ pese a la existencia de fragmentos áticos que ella misma fecha en el s. VI y en torno al $500 \mathrm{aC}$; reconoce la antiguedad del yacimiento junto a La Alcudia y La Escuera frente a los restantes yacimientos de la provincia de Alicante que atribuye de manera genérica al s. IV aC (NORDSTRÖM, 1973, 30-31). Llobregat (1972, 92), por su parte, no modificó esta datación. En el estudio más reciente de M. Monraval (1992, 126) se establecen correctamente los márgenes cronológicos que proporcionan los materiales de importación si bien, a nuestro juicio, no se acaba de realizar una valoración justa de esta necrópolis. Hoy queda claro que se trata de la necrópolis del poblado de El Oral.

El nivel ibérico antiguo de La Alcudia (Elche) sólo se ha detectado en algunos puntos cuando se han acometido trabajos de excavación en vertical. La información es escasa -se conocen únicamente y de manera aislada algunos vasos cerámicos y otros objetos domésticos-, pero hasta el descubrimiento de El Oral constituía la única muestra de un hábitat ibérico antiguo.

La necrópolis de Altea la Vella (Altea) se conocía por unas breves notas de Almarche y F. Martínez sobre el hallazgo de algunos objetos que calificaban el yacimiento como antiguo (LLOBREGAT, 1972, 109). Por desgracia, los materiales más significativos se descubrieron en una excavación clandestina de unos coleccionistas, si bien la información pudo recuperarse parcialmente (MOROTE, 1981). En 1981, 
con motivo de unas obras en una vivienda del caserío actual de Altea la Vella, se descubrió lo que sus excavadores interpretaron como restos de un vertedero de carácter doméstico, con lo que queda claro que el hábitat se localiza justo debajo del núcleo de población moderno.

El poblado de El Oral (San Fulgencio), situado en la misma desembocadura del río Segura, es un yacimiento que había permanecido intacto y desconocido para la investigación. Su estratégica ubicación y el hallazgo en superficie de materiales con claras analogías con el contexto material de Peña Negra motivó el inicio de su excavación con una primera fase de cinco campañas (ABAD y SALA, 1993); los trabajos de campo continuan en la actualidad dentro de una segunda fase de excavaciones que están ofreciendo una interesante información complementaria de lo ya publicado.

En la actualidad el número de yacimientos del País Valenciano pertenecientes a la fase antigua ha ido creciendo con la práctica de prospecciones sistemáticas, por un lado, y el progresivo conocimiento del contexto material, por otro (BONET y MATA, 1994, 161). Con todo, no dejan de ser puntos mudos en un mapa de distribución al tratarse en la mayoría de los casos de hallazgos cerámicos superficiales. En estas condiciones resulta prematuro emprender estudios espaciales del territorio porque faltan elementos de juicio mensurables, incluso para una zona con mayor información como son las comarcas meridionales alicantinas. No obstante, contamos con la ventaja de que $\mathrm{E}$ O Oral ofrece un contexto material amplio y fiable de este período $\mathrm{y}$, por tanto, si se contrasta con otros yacimientos permitirá recuperar los datos hasta ahora inconexos o sin fiabilidad alguna. Estamos pues en condiciones de poder presentar algunos de los rasgos de la fase ibérica antigua contestana que exponemos seguidamente con breves comentarios en espera de una autentica normalización.

\section{LA IDENTIDAD DE LO IBÉRICO ANTIGUO CONTESTANO}

\section{III.1. El poblamiento}

Paralelamente, el número de yacimientos protohistóricos y orientalizantes en el País Valenciano también ha ido en aumento, comprobándose que se situan indistintamente en el interior o en la costa pero siempre vertebrados en torno a los ejes fluviales más importantes; este panorama desmiente las primeras tesis que señalaban un poblamiento esporádico y distribuido de manera irregular. Opiniones más recientes aducen cambios en la estrategia de ocupación del territorio al iniciarse la época ibérica antigua (BONET y MATA, 1994, 160-161), pero si es cierto que algunos poblados protohistóricos se abandonan en torno a mediados del s. VI aC y surgen ex novo una parte de los ibéricos, muchos mantienen una ocupación continuada, de lo que se deduce un poblamiento más estable de lo que imaginamos. La intensidad y distribución de enclaves que va conociéndose para la fase ibérica antigua refleja un modelo 
bastante similar al del período anterior; quizá factores más circunstanciales que de orden cultural expliquen algún día los abandonos de algunos enclaves y el traslado de la generación posterior ya ibérica a otro lugar.

Con un simple examen del mapa de distribución (Fig. 1) se entrevé lo que se manifiesta como un rasgo significativo: el reducido poblamiento. No podemos negar que el número de yacimientos se vea ampliado a medida que avance la investigación, pero no creemos que llegue a alcanzar el total de yacimientos de época plena, que es cuando se produce un crecimiento de población realmente manifiesto. Por otro lado, si nos detenemos en la situación concreta en relación con el medio físico observaremos que los enclaves contestanos se encuentran en la línea costera y junto a la desembocadura de un río. La ubicación de La Alcudia no nos debe llevar a engaño porque si en el mapa actual parece relativamente alejada de la costa, en la antigüedad se encontraba en el límite de la zona lagunar navegable en la que se fundían los ríos Segura y Vinalopó en su salida al mar, luego a todos los efectos situada en la antigua línea costera. El poblamiento antiguo contestano no se diferencia en este sentido de lo que se observa en otras regiones: un poblamiento escaso, reducido a pocos enclaves junto a ejes fluviales de importancia o preferentemente en sus desembocaduras si se trata de áreas litorales².

Parece deducirse de estas palabras que el interior estuvo despoblado, pero no es así en absoluto. Recientes prospecciones en los valles de la montaña alicantina documentan una serie de hallazgos superficiales de cerámica fenicia e ibérica antigua que indican la existencia de un poblamiento de estas fechas cuyas características esperamos conocer pronto (MARTÍ y MATA, 1992). Por otro lado, los materiales fenicios descubiertos en El Monastil (Elda) (POVEDA, 1995) confirman la continuación del hábitat desde la Edad del Bronce hasta enlazar con el poblado ibérico, cuya fase antigua ya se conocía, y se añade así otro punto más en el interior, el valle medio del Vinalopó. No es válida la idea de un poblamiento reducido a la costa, pero sí parece perfilarse una cierta diferencia: en los valles del Alcoià-Comtat, la mayoría de los puntos de hallazgos registran cerámica fenicia junto con ibérica antigua, y en buena parte de ellos incluso cerámica a mano prehistórica, de lo que parece deducirse casi como norma la continuidad en los hábitats, evidente en el caso de El Monastil; en la costa, por el contrario, es donde se dan las fundaciones ex novo de pobla-

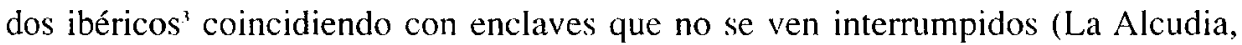
Saladares). Parece que si hay algún movimiento de población entre el final del período protohistórico y el inicio del mundo ibérico, éste tiene lugar en los territorios

En las ponencias del Congreso de Ján (1987) se describe un poblamiento en las fases aniguas de las respectivas regiones ibéricas como el que acabamos de enunciar.

A los ejemplos de El Oral y Altea la Vella hay que añadir orro poblado costero en Calpe, a unos $10 \mathrm{~km}$. al norte de Altea, descubicrto recientemente por J. Casabó. En el caso de la Sicra de Crevillente, es también válida esta idea porque después de abandomarse Peña Negra el poblamiento ibérico reaparece instalado en otro cerro cercano. el Cas tellar Roig. en la segunda mitad del s. V aC. 
costeros. Habría que calibrar hasta qué punto no es éste un rasgo propio de la Contestania, porque en las costas del norte de Valencia y Castellón los poblados costeros con niveles ibéricos antiguos conocidos hasta ahora suelen presentar un hábitat continuo desde fines del s. VII aC.

\section{III.2. La arquitectura y el urbanismo}

Si la aplicación de nuevos instrumentos de análisis en la arqueología ibérica ha permitido erradicar el viejo concepto de los asentamientos instalados en puntos altos y sin ningún tipo de organización, una de las principales contribuciones de El Oral ha sido la de mostrar que existe un urbanismo regular y planificado desde la misma fase inicial de la Cultura Ibérica (Fig. 2). Pese al ejemplo tan claro no podemos afirmar que este urbanismo esté generalizado, ni siquiera en las comarcas meridionales de la Contestania, sencillamente porque es el único poblado de este momento excavado en extensión. Imaginamos que su implantación o no se vería supeditada sobre todo a las condiciones topográficas y, en ese sentido, es bastante probable que en el futuro podamos contemplar un urbanismo regular en La Alcudia, o que Altea la Vella presente un urbanismo en ladera, a juzgar por la topografía del cerro donde se levantan ambos poblados; Los Villares (Caudete de las Fuentes, Valencia), otro poblado del País Valenciano con un nivel antiguo bastante conocido, presenta un urbanismo de calles cruzadas en ángulo recto, pero se data en el s. IV aC (MATA, 1991, fig. 2, 1); del urbanismo del Puig de la Nau, en el norte de Castellón, también se dice que es de tipo regular (OLIVER y GUSI, 1995, 191) pese a que el espacio exhumado es todavía reducido. En cualquier caso, la idea que debe prevalecer es que desde los mismos orígenes de lo ibérico existe una elección del espacio habitable y la capacidad de organizarlo de manera racional según las necesidades de la comunidad que se fuera a instalar; los elementos de infraestructura comunitaria descubiertos en El Oral, como por ejemplo los canales de desagüe previstos ya antes de la construcción de la muralla o los espacios públicos, son una prueba de la madurez alcanzada en esta función.

Los poblados contestanos, como casi todos los ibéricos, quedan definidos ante todo en cuanto a su condición de asentamientos por la presencia de un recinto defensivo quc, además, es el delimitador del espacio urbano frente al extraurbano (BONET ef alii, 1994, 115). El simposio sobre fortificaciones celebrado en Manresa en 1990 (VV.AA., 1991) sirvió para poner de manifiesto la complejidad que pueden alcanzar los sistemas defensivos ibéricos de época clásica, que en este aspecto siguen en alguna medida la evolución de la poliorcética mediterránea dictada desde el mundo griego y púnico. No obstante, llegados a este punto es cuando se nota la falta de un estudio evolutivo de las fortificaciones que es necesario emprender ante los indicios de ciertas diferencias entre la fase antigua y la plena. Por lo general, los pobla- 
dos contestanos de época clásica presentan murallas jalonadas por pequeños torreones, normalmente macizos y de planta rectangular, situados a una distancia más o menos regular entre sí y sobresaliendo muy poco del lienzo externo. Para las fortificaciones de la fase antigua contamos con el ejemplo de El Oral que muestra un sistema sustancialmente distinto: consiste en una muralla no muy ancha pero construida con un basamento ciclópeo, que sólo presenta dos grandes torreones exentos y macizos erigidos a ambos lados de la puerta para proteger la entrada, pese a que no había impedimentos topográficos para haber construido algunos más.

Aunque existen algunos ejemplos en fechas posteriores, la muralla de El Oral tiene sus paralelos en el sistema defensivo mediterráneo de estrategia "pasiva», cuyo auge tiene lugar en época arcaica (ABAD y SALA, 1993, 198) pero que remonta su origen a las fortificaciones griegas y orientales de la segunda mitad del II milenio. Los paralelos ibéricos en los poblados de Tossal del Moro de Pinyeres (Tarragona) (ARTEAGA et alii, 1990, 155 ss.) y Santa Pola (Alicante), ambos de fecha antigua, nos reafirman en la sospecha de que los enclaves ibéricos antiguos se siguen fortificando siguiendo una tradición anterior ya conocida, y que esta situación cambia en los inicios del s. IV aC coincidiendo cronológicamente con las innovaciones de la poliorcética adaptándose a la evolución de las tácticas de guerra en el Mediterráneo.

En el interior del recinto defensivo, las casas se organizan según un trazado viario y se construyen con la técnica y materiales constructivos que ya se empleaban en los poblados protohistóricos. Hasta que no se llega a época plena, no es fácil distinguir edificios destacables de tipo no doméstico, y aún entonces se diferencian más por la singularidad de la planta que porque destaque algún elemento arquitectónico en sí. Las viviendas domésticas o artesanales están provistas de estructuras idénticas de barro o de mampostería cuyas diferentes funciones sólo pueden deducirse a través del contexto arqueológico.

\section{III.3. Sobre el ajuar de uso cotidiano}

El contexto material de este momento se conocía muy parcialmente gracias a los hallazgos de la necrópolis de El Molar y de La Alcudia; las excavaciones de El Oral, por su parte, han servido para confirmar los conjuntos anteriores y elaborar una tipología más completa con nuevos vasos y otros objetos. El ajuar doméstico de las viviendas de El Oral ha sido ya estudiado (ABAD y SALA, 1993, 201 SS.) y sus rasgos más importantes contrastados con los del ajuar de época clásica (SALA, 1995), lo que nos exime de describirlo de nuevo. Destacaremos tan sólo aquellos que sirven mejor a nuestro propósito.

En El Oral aparecen una serie de vasos que seguirán utilizándose en usos domésticos hasta la romanización con variaciones formales más o menos significativas: 
son los vasos de almacenaje como urnas, pithoi y lebetes, la vajilla de mesa compuesta por platos, caliciformes o cubiletes, y las ollas de cocina hechas a torno con pastas de calidad muy grosera. Lo que nos interesa son, no obstante, los vasos que sólo se encuentran en estos contextos antiguos: son precisamente los que reflejan la herencia del período orientalizante de la zona y del mediodía peninsular sin perder su identidad ibérica.

Las ánforas, por ejemplo, son el resultado final del proceso de transformación que experimentan las producciones anfóricas protohistóricas desde las primeras imitaciones de las R1 fenicias: han abandonado ya el hombro carenado, son un poco mayores de tamaño, pero siguen manteniendo la forma general de saco y los bordes bastante destacados del cuerpo (Fig. 3, 1). Pese a que se documentan distintos perfiles en los bordes (ABAD y SALA, 1993, 206-207), en realidad sólo existe el tipo de envase que acabamos de describir, un envase único como en época protohistórica. A fines del s. V, con el inicio del ibérico clásico, el repertorio cerámico cambia notablemente y en el caso de las ánforas empieza la diversificación de formas, hecho que interpretamos como consecuencia de la diferenciación comercial de los contenidos (SALA, 1995) (Fig. 3, 2-3).

Entre la cerámica pintada tenemos un ejemplo muy significativo con las jarras tipo Toya. Este vaso, cuyo antecedente se halla en las urnas Cruz del Negro, aparece en la necrópolis de Toya como uno de los vasos cinerarios más utilizado y allí se fechó a fines del s. VI y principios del s. V aC (PEREIRA, 1979, 326). Recientemente se ha propuesto una nueva datación del yacimiento en la primera mitad del s. IV aC basándose en la cerámica ática (SÁNCHEZ, 1992), no obstante, su aparición en El Oral con la misma cronología que la primera propuesta confirma que es un vaso propio de los contextos ibéricos antiguos. Así adquieren sentido los ejemplares de las necrópolis antiguas de El Molar (MONRAVAL, 1992, 41, n. 21-22; NORDSTRÖM, 1973, Pl. 9) y La Solivella (Castellón) (FLETCHER, 1965, fig. 20), donde también se utilizan como contenedores funerarios. Presentan además distintas variantes, desde las que siguen fielmente el modelo, como las de Toya (Fig. 4, 4), las que copian los elementos formales pero no la proporción, como las de El Oral (Fig. $4,1-2$ ), hasta las que interpretan libremente la forma, como los ejemplares de las necrópolis citadas (Fig. 4,3), lo que indica la asimilación total de este vaso en el repertorio de la alfarería ibérica antigua.

Un argumento similar podría esgrimirse para las urnas de orejetas, el vaso característico por excelencia del ibérico antiguo. Aunque se acepte que la urna de orejetas es una interpretación indígena del concepto de cierre hermético de la alfarería mediterránea oriental (PEREIRA y RODERO, 1988, 50-52), los ejemplares ibéricos contestanos más antiguos (El Molar, El Oral, Altea la Vella, La Alcudia) toman su modelo de los ejemplares hallados en poblados orientalizantes del Sureste, en la cercana Peña Negra (GONZÁLEZ PRATS, 1983, 224-225) o en Los Almadenes, en la 
provincia de Albacete (SALA y LÓPEZ, 1995), siendo éstos los únicos paralelos conocidos de estas fechas. En época plena todavía se utilizará como urna cineraria, aunque ya en contadas ocasiones, y con una forma general bastante menos estilizada.

Precisamente en la decoración de estos vasos, la jarra tipo Toya y una de orejetas, se plasman como motivos una serie de triángulos rellenos con un enrejado y una doble línea quebrada rellena de pequeños trazos perpendiculares respectivamente, cuyos paralelos exactos se encuentran en la cerámica a mano pintada de El Carambolo (ABAD y SALA, 1993, 225).

Otros vasos significativos son las fuentes de asas de espuerta y de asas horizontales, exclusivas asimismo del ajuar ibérico antiguo (Fig. 3, 4). Los paralelos de ésta última no están claros, pero en el caso de la primera sí tienen su modelo claro en las fuentes con asas de espuerta que ya aparecen en Setefilla hechas a torno lento y que después se encuentran elaboradas a torno en factorías fenicias y poblados protohistóricos de la Alta Andalucía y Sureste (ABAD y SALA, 1993, 220). El ejemplar encontrado en El Oral tiene su paralelo más próximo en las fuentes de Peña Negra fechadas en la primera mitad del s. VI aC, pero también aparece en el poblado de Altea la Vella y en el témenos del Parque de Elche (RAMOS y RAMOS, 1992, fig. 506-508), lo que parece indicar que es un vaso particular del área contestana pese a no ser muy abundante. Hacia el norte, los ejemplares de forma más aproximada proceden del nivel del s. III aC de Los Villares (Valencia) y están fabricados en cerámica de cocina (MATA, 1991, fig. 60, 2-5).

Podríamos comentar otros datos, como los perfiles de los platos con paralelos en los de ala de barniz rojo meridionales, pero pierden relevancia por ser un recipiente muy extendido. Sin embargo, en el ajuar de El Oral hay un grupo cerámico, la cerámica gris, que muestra claramente la herencia del poblamiento orientalizante de la zona, ya que tanto las formas como las calidades de fabricación o su porcentaje dentro del conjunto están calcadas del repertorio de Peña Negra. Otro ejemplo tan lejano como la necrópolis de Medellín (Badajoz), donde la cerámica gris constituye el conjunto cerámico más numeroso y la variedad de su repertorio es asimismo notable (LORRIO, 1988-89, 284 ss.), confirma la adecuación de esta producción en los períodos orientalizante e ibérico antiguo. En contra de la opinión generalizada, el auge de este tipo de cerámica se da en la fase antigua y no en la plena: en los poblados contestanos de época clásica los vasos grises prácticamente han desaparecido, y los pocos ejemplares que se encuentran se limitan a copias de formas áticas de barniz negro. La falta de información contrastable de otras zonas impide calificarlo como un comportamiento propio de la Contestania, pero sí queda claro que los habitantes de El Oral estaban perpetuando el uso de cerámica reductora que recibieron de sus antecesores protohistóricos (ABAD y SALA, 1993, 214-219, fig. 165-166). 


\section{III.4. EI horizonte de importaciones}

Otra de las contribuciones de El Oral ha sido la de haber podido caracterizar un conjunto de importaciones que hasta ahora se conocía por hallazgos submarinos casuales (FERNÁNDEZ IZQUIERDO et alii, 1988), o procedentes de excavaciones pero igualmente carentes de contexto (ROUILLARD, 1991).

En El Oral se han documentado ánforas griegas -massaliotas, corintias B, quiotas- junto con etruscas y fenicio-púnicas de la zona de Cádiz -las Tagomago o tipo Mañá-Pascual A4-, todo ello asociado a una vajilla de lujo compuesta únicamente por cerámica ática de barniz negro y posiblemente figuras negras tardías (ABAD y SALA, 1993, 201-206; SALA, 1995). Este horizonte se va confirmando y completando a medida que aparecen nuevas memorias de excavaciones, por ejemplo, en el recientemente publicado poblado del Puig de la Nau (Benicarló, Castellón), además de 4 ánforas massaliotas sus excavadores hablan de una imitación indígena de ánfora massaliota, que podría tratarse más bien de un ejemplar «jonio-massaliota» (GUSI y OLIVER, 1995, 174, fig. 30).

Si a los hallazgos de El Oral sumamos los de su necrópolis, El Molar, tenemos un conjunto que se aproxima al horizonte de importaciones que a lo largo del s. VI aC presentan lugares tan significativos como Ampurias, Málaga, Huelva y la zona de Cádiz. La cantidad total de importaciones en $\mathrm{El}$ Oral y su necrópolis son lógicamente más reducidas -como era de esperar en un centro de menor importancia-, sin embargo, al comparar porcentajes relativos con los yacimientos citados no se aprecia la recesión económica atribuida al final del periodo orientalizante, ni siquiera la pérdida de valor de algún producto sobre el resto: la vajilla de lujo es sólo ática y llega en escaso número continuando así el comportamiento comercial que se anunciaba a principios del s. VI aC; las ánforas griegas son asimismo pocas, hecho que va en consonancia con el uso elitista que se atribuye al producto que contenían, vino o aceite. Aunque habría que profundizar en este tema, el papel que estas importaciones griegas representan en la sociedad ibérica antigua parece estar próximo todavía al concepto de bienes de prestigio que regía en el sistema de reciprocidad del comercio de los siglos VIII-VII aC en la Península Ibérica (CABRERA BONET, 1994, 24-28).

Estos productos venían acompañados de manufacturas de carácter suntuario, muchas de las cuales se han perdido. Las que nos han dejado constancia son principalemente objetos de bronce, por ejemplo, olpes de origen etrusco del tipo de El Oral (Fig. 3, 5), figurillas o apliques figurados como el sátiro del LLano de la Consolación (Albacete), el Centauro de Royos (Murcia) o el asa del enterramiento de Pozo Moro (Albacete), que gracias al pecio francés de la Pointe Lequin $1 \mathrm{~A}$ de fines del s. VI aC (LONG et alii, 1992) sabemos que se importaban en su estado fragmentado.

El cargamento completo de este pecio, con ánforas y vajilla de lujo griegas, en su condición de «hallazgo cerrado» verifica la autenticidad del horizonte de impor- 
taciones que se está empezando a conocer en El Oral y en otros poblados ibéricos antiguos. Un contexto cualitativamente similar al que aparece en el s. VI aC y primera mitad del s. $\mathrm{V}$ en centros etruscos y en ciudades griegas e indígenas de la Magna Grecia y de las islas centromediterranéas (SALA, 1995). Un contexto de importaciones, en suma, que muestra más el final del ambiente comercial tardoarcaico que una situación de ruptura con la tradición anterior y la formación de un orden económico y social nuevo.

\section{III.5. Sobre las costumbres funerarias}

Los íberos se entierran según un ritual que está establecido desde los primeros momentos y no experimenta modificaciones en su esencia. Cuando se aprecian variaciones es en la tipología de los objetos del ajuar, en su mayor o menor riqueza y en la existencia de tumbas o señalizaciones monumentales; estas diferencias, que son evidentemente manifestaciones externas de orden social, se deben a factores cronológicos y de delimitación territorial.

En el área levantina la reciente publicación de dos síntesis (ABAD y SALA, 1992; MATA, 1993) ha servido para elaborar una idea general sobre el comportamiento funerario de los íberos de esta zona, sólo un punto de partida para futuras investigaciones ya que también han servido para plantear nuevas cuestiones. De la revisión de las necrópolis antiguas, por ejemplo, se deducen unos rasgos comunes que indican un ritual característico de la fase ibérica antigua: deposición de las cenizas en hoyos, bien directamente, bien en urnas, preferencia por las urnas de orejetas como vaso cinerario seguida de las jarras que imitan las urnas Cruz del Negro, austeridad generalizada en los ajuares que se limitan a objetos de indumentaria personal y escaso armamento, austeridad incluso en la construcción y señalización de los enterramientos ${ }^{4}$ (ABAD y SALA, 1992, 151-160; ABAD et alii, 1994-95). Hasta ahora todo sería normal si no fuera por algunos hechos en las necrópolis contestanas que no han sido suficientemente valorados.

Nos referimos, en primer lugar, a la existencia de dos inhumados en la necrópolis de El Molar. Monraval resuelve esta cuestión atribuyendo una primera fase no ibérica fechada en el s. VI aC a la que pertenecerían las importaciones griegas más arcaicas y las inhumaciones; después se sucedería la fase propiamente ibérica con las incineraciones a partir del s. $\mathrm{V} \mathrm{aC}$. Una solución cuestionable si al leer a Lafuente vemos que uno de los inhumados, el que fue enterrado en una cista de seis grandes losas, poseía como ajuar un escarabeo y una cuenta de pasta vítrea (LAFUENTE, 1929, 621). La tumba de la supuesta segunda inhumación ya había sido arrasada cuando llegó Lafuente, pero dedujo su existencia porque se construyó con losas idén-

\footnotetext{
${ }^{4}$ Con la excepción de las umbas monumentales del tipo pilar-estela cuya existencia se deduce de la escultura y de alguna pieza arquitectónica.
} 
ticas a las anteriores que, suponía, formaban una cámara sepulcral. Senent aporta más detalles afirmando que al ser desmontado el «pequeño montículo formado por piedras colocadas intencionalmente y tierra sobrepuesta» los propietarios del terreno encontraron un pendiente de oro y un braserillo de bronce entre los restos de lo que según él «tenía todas las trazas de una o varias sepulturas en cámara tumular» (SENENT, 1930, 3). Unos ajuares que coinciden con el resto de los enterramientos de incineración. Por otro lado, al comparar las urnas cinerarias con la cerámica de El Oral encontramos que todos los vasos se corresponden con el repertorio del poblado, luego la necrópolis -o al menos la zona excavada- tendría un solo nivel contemporáneo a la ocupación del hábitat. Si aceptamos estos hechos, deberíamos admitir la presencia de dos inhumados en la necrópolis ibérica, es decir, dos extranjeros en una comunidad que practica la incineración, dos miembros de otra comunidad a los que les llegó la muerte residiendo temporal o permanentemente en este lugar. ¿Quién se inhuma en estas fechas en la Península?. Un griego o un púnico, si bien los ajuares concuerdan con el rito de las inhumaciones púnicas fechables a partir del s. VI aC (RAMOS SAINZ, 1986, 85), y el tipo de tumbas, en concreto el de la cista de losas, recuerda sobre todo las cistas de la necrópolis de Jardín, y algunos ejemplos de Villaricos y Cádiz (Fig. 6) (RAMOS SAINZ, 1986, 43).

Almagro relacionaba las tumbas de cámara y las cajas funerarias ibéricas con el mundo orientalizante traido por la colonización fenicia. Según este autor, el área de dispersión de ambos elementos centada en la Alta Andalucía ofrecía una clara relación con las factorías fenicias de la costa mediterránea; la cámara de Archena, fuera del territorio principal, se explicaba como una extensión de este elemento desde la Bastetania hacia las tierras altas del Segura. Afirma asimismo que estas cajas de piedra estarían destinadas a ser depositadas en las cámaras funerarias (ALMAGRO GORBEA, 1982, 252). ¿Podría esto explicar la presencia de un larnax de piedra arenisca en El Molar?.

La necrópolis de Altea la Vella ofrece otro elemento que merece nuestra atención. La deposición de las cenizas se realizó en urnas de orejetas introducidas en simples hoyos tapados después con losas; no se menciona ningún tipo de señalización a excepción de una estela que apareció entre las urnas en su posición original vertical (MOROTE, 1981, fig. 3). Se trata de una losa rectangular de superficies alisadas en la que se ha representado mediante trazo inciso la figura de un guerrero, con un vestido talar sujeto por un cinturón y armado con una espada de antenas y un cuchillo afalcatado; la estela apareció sin la cabeza que debió perder de antiguo a juzgar por la fractura (Fig. 5,1). Es un unicum en la estatuaria ibérica que no presenta relación alguna con las estelas del Suroeste ni con las ibéricas tardías de los siglos II-I aC, que son asimismo escasas y se limitan a inscripciones en lengua ibérica; por este aislamiento, en parte, y por el desconocimiento de la necrópolis, apenas ha sido objeto de interés. Hoy seguimos sin poder aportar mucho más, tan sólo comentar a 
título de curiosidad que los ejemplos estilísticamente más cercanos se encuentran en las estelas masculinas daunias del s. VI aC continuadoras de la tradición de escultu-

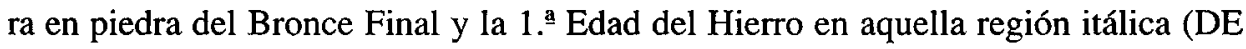
JULIIS, 1988, 80, lám. 32). Con este paralelo no pretendemos explicar su presencia en un arte ibérico caracterizado por la estatuaria de bulto redondo o de altorrelieve, pero sí nos permite la sospecha de que cualquiera que fuera su origen, éste radicaría en la tradición anterior.

Resumiendo, inhumados, uno de ellos en una cista tipo Jardín, una posible tumba de cámara tumular, una incineración en un larnax, una estela de guerrero... aspectos raros en dos necrópolis contestanas que en todo los demás responden como tales. Quizá no sea necesario extender las influencias culturales bastetanas hasta el Bajo Segura para explicar estos hechos atípicos, ¿por qué no pensar en la permanencia temporal en esta zona de gentes de otras regiones peninsulares a principios del s. V por motivos de comercio, por ejemplo?. Resulta una hipótesis sin duda sugerente, tanto más cuando leemos a J. de Hoz afirmar que el ibérico parece tratarse de una lengua vehicular surgida por razones económicas en la Contestania, y que ello da sentido a la presencia de íberos en Pech-Maho en relaciones comerciales con colonos focenses e indígenas, testificada en la tablilla de plomo fechada en el $\mathrm{s}$. $\mathrm{V} \mathrm{aC}$ hallada en este puerto francés (DE HOZ, 1993, 656 ss.).

\section{A MODO DE REFLEXIÓN FINAL}

Pese a la tradición del iberismo iniciada a principios de siglo en el Sureste, País Valenciano y la Contestania, en la actualidad no se puede decir que el conocimiento en esta zona sea mayor que en el resto de las regiones ibéricas. Por ello no hay otro modo de empezar estas conclusiones más que retomando las palabras introductorias.

Es verdad que se han realizado avances notables que han permitido publicar recientemente algunas síntesis de gran validez y que han solucionado graves errores iniciales heredados de los primeros pasos de la investigación. Lo que han hecho en definitiva ha sido preparar el terreno para que a partir de ahora se puedan emprender estudios de aspectos más concretos hechos con una metodología y un marco teórico actualizado. La investigación ibérica se halla precisamente en este punto, lo queramos o no, no hemos sobrepasado la fase descriptiva, la fase de presentación de datos que en un futuro próximo habrá que interrelacionar hasta obtener normas generales. No porque la información disponible hoy sea errónea, sino porque es insuficiente y necesita de otros datos contrastables.

Conscientes de esta realidad, no hemos pretendido conseguir una síntesis en la que se fueran desgranando punto por punto las características del período ibérico antiguo contestano presentándolas con carácter definitivo. En el capítulo del poblamiento está practicamente todo por hacer, habría que empezar por aproximarse al nú- 
mero total de yacimientos y averiguar su extensión para poder confeccionar una jerarquía de asentamientos a partir de la cual hablar de características de los hábitats, del dominio del territorio y si existe alguna capitalidad"; lo que aquí se ha expresado acerca del poblamiento no son más que ideas esbozadas como planteamientos de futuros trabajos encaminados a conseguir esta información. En el urbanismo y la arquitectura la aparición de El Oral ha supuesto un gran avance, aunque huelga decir que el beneficio efectivo que reporte a la investigación se conseguirá cuando se pueda contrastar con otros poblados antiguos contestanos y del Levante peninsular. Lo mismo se puede decir en lo referente a los contextos materiales, tanto en los ajuares domésticos como en los productos objeto de comercio, si bien en estos aspectos la información es más completa y sólo habría que ir añadiendo matices nuevos que proporcionen otros yacimientos. El mundo funerario necesitaría ahora de un trabajo monográfico dedicado a las costumbres funerarias de la fase antigua en donde poder insertar y explicar los enterramientos atípicos comentados más arriba.

En cualquier caso, y esa es la idea que ha inspirado este trabajo, lo que reivindicamos es que el mundo ibérico antiguo contestano -y creemos que podría generalizarse a toda la Península - en lo que conocemos hasta ahora no parece suponer una ruptura drástica con respecto al poblamiento anterior. Hemos visto cómo muchos elementos son la continuación de la tradición orientalizante o están inspirados en ella, en el caso de la Contestania todo nos remite al poblamiento orientalizante y colonial del Sureste y del mediodía peninsular. Tal es así que estamos convencidos de que el ibérico antiguo constituye más bien el momento final del orden social y económico arcaico que el inicio de una nueva etapa. Ésta en realidad se produce a fines del s. V cuando se inicia la fase clásica o plena porque es a partir de ahora cuando tiene lugar un aumento notable del poblamiento que supone la instalación de hábitats en valles secundarios deshabitados hasta entonces, se producen innovaciones en los sistemas defensivos, cambia la vajilla cerámica, cambia la situación comercial con la entrada masiva de la vajilla fina ática y la irrupción de los productos púnicos, es también el momento en el que se fecha la mayoría de las destrucciones de escultura y cuando aparecen los ricos ajuares funerarios y las panoplias completas, signo de una clase social guerrera emergente, $\ldots$ y otros muchos elementos que son mercedores de ser analizados desde esta perspectiva en otro trabajo.

\section{BIBLIOGRAFÍA}

ABAD, L. 1987: «El poblamiento ibérico en la provincia de Alicante», Iberos. Actas de las I Jornadas sobre el Mundo Ibérico (Jaén, 1985), Jaén.

"Actualmente en el área de Arqueología de la Universidad de alicante se están realizando dos tesis doctorales que tratan el tema del territorio ibérico contestano desde esta misma perspectiva. 
ABAD, L. y SALA, F. 1992: «Las Necrópolis ibéricas del área de Levante», Congreso de Arqueología Ibérica. Las necrópolis, Serie Varia, 1, Universidad Autónoma de Madrid, Madrid.

ABAD, L. y SALA, F. 1993: El poblado ibérico de El Oral (San Fulgencio, Alicante), T.V. del S.I.P., 90, Valencia.

ABAD, L.; SALA, F. y ALBEROLA, E. 1994-95: «La necrópolis y el área sacra ibéricas de «Las Agualejas» (Monforte del Cid, Alicante)», Lucentum, XIII-XIV, Alicante.

ARTEAGA, O. y SERNA, M.A. 1975: «Los Saladares-71», N.A.H., Arqueología, 3, Madrid.

ARTEAGA, O; PADRÓ, J. y SANMARTÍ, E. 1990: El poblado ibérico del Tossal del Moro de Pinyeres (Batea, Terra Alta, Tarragona), Institut de Prehistòria i Arqueologia, Monografies Arqueològiques, 7, Barcelona.

BONET, H. y MATA, C. 1994: «La Cultura Ibérica en el País Valenciano: estado de la investigación en la década 1983-1993», Actes de les Jornades d'Arqueologia (Alfàs del Pi, gener 1994), Generalitat Valenciana, Valencia.

BONET, H.; GUÉRIN, P. y MATA, C. 1994: «Urbanisme i habitatge ibèrics al País Valencià», Cota Zero, 10, Vic.

CABRERA BONET, P. 1994: «Comercio internacional mediterráneo en el siglo VIII a.C.», AEspA, 67, Madrid.

CAZURRO, M. y GANDÍA, E. 1913-14: «La estratificación de la cerámica en Ampurias y la época de sus restos», Anuari del Institut d'Estudis Catalans, Barcelona.

DE HOZ, J. 1993: «La lengua y la escritura ibéricas, y las lenguas de los íberos», Lengua y Cultura en la Hispania prerromana, Actas del V Coloquio sobre Lenguas y culturas prerromanas de la Península Ibérica (Colonia, 25-28 de noviembre de 1989), Ediciones Universidad de Salamanca.

DE JULIIS, E. 1988: Gli Iapigi. Storia e Civiltà della Puglia preromana, Longanesi \& C., col. Archeologia, 8, Milán.

FERNÁNDEZ IZQUIERDO, A.; GÓMEZ BELLARD, C. y RIBERA LACOMBA, A. 1988: «Las ánforas griegas, etruscas y fenico-púnicas en las costas del País Valenciano», Navies and commerce of the greeks, the carthaginians and the etruscans in the Tyrrhenian Sea (Ravello, 1987), PACT, 20, Rixensart.

FLETCHER, D. 1965: La necrópolis de La Solivella (Alcalá de Chivert), T.V. del S.I.P., 32, Valencia.

GONZÁLEZ PRATS, A. 1983: Estudio arqueológico del poblamiento antiguo de la Sierra de Crevillente (Alicante), Anejo I de la Rev. Lucentum, Universidad de Alicante. 
GUSI, F. y OLIVER, A. 1987: «La problemática de la iberización en Castellón», Iberos. Actas de las I Jornadas sobre el Mundo Ibérico (Jaén, 1985), Jaén.

JUNYENT, E. ; OLARIA, C.; GUSI, F.; AGUILO, P.; ROMÁN, I. y SESER, R. 1982-83: «El Abric de Les Cinc (Almenara, Castellón). 2. Campaña de excavaciones 1977», C.A.P.C., 9, Castellón.

LLOBREGAT, E. 1972: Contestania Ibérica, Instituto de Estudios Alicantinos, Alicante.

LONG, L.; MIRÓ, J. y VOLPE, G. 1992: «Les épaves archaïques de la pointe Lequin (Porquerolles, HYères, Var). Des données nouvelles sur le commerce de Marseille à la fin du VIe. et dans la première moitié du Ve. s. av. J.-C.», Marseille grecque et la Gaule, Colección Etudes Massaliètes, 3.

LORRIO, A.J. 1988-89: «Cerámica gris orientalizante de la necrópolis de Medellín (Badajoz)», Zephyrus, XLI-XLII, Salamanca.

MARTI, M.A. y MATA, C. 1992: «Cerámicas de tipo fenicio occidental en las comarcas de l'Alcoià y El Comtat», Saguntum, 25, Valencia.

MATA, C. 1991: Los Villares (Caudete de las Fuentes, Valencia). Origen y evolución de la Cultura Ibérica, T.V. del S.I.P., 88, Valencia.

MATA, C. 1993: «Aproximación al estudio de las necrópolis ibéricas valencianas», Homenatge a $M$. Tarradell, Ed. Curial, Barcelona.

MONRAVAL, M. 1992: La necrópolis ibérica de El Molar (San Fulgencio-Guardamar, Alicante), Catálogo de fondos del Museo Arqueológico Provincial, V, Alicante.

MOROTE BARBERÁ, G. 1981: «Unas estela de guerrero con espada de antenas en la necrópolis ibérica de Altea la Vella (Altea, Alicante)», A.P.L., XVI, Valencia.

NORDSTRÖM, S. 1973: La céramique peinte ibérique de la province d'Alicante, Estocolmo.

OLIVER, A. y GUSI, F. 1995: El Puig de la Nau. Un hábitat fortificado ibérico en el ámbito mediterráneo peninsular, Monografies de Prehistòria i Arqueologia castellonenques, 4, Diputación de Castellón, Castellón.

PEREIRA SIESO, J. 1979: «La cerámica ibérica procedente de Toya en el M.A.N.», T.P., 36, Madrid.

PEREIRA, J. y RODERO, A. 1983: «Aportaciones al problema de las urnas de orejetas perforadas", Homenaje al Prof. M. Almagro Basch, III, Madrid.

POVEDA, A. 1995 (e.p.): «Penetración cultural fenicia en el territorio indígena del valle septentrional del Vinalopó (Alicante)», IV Congreso Internacional de Estudios Fenicios y Púnicos (Cádiz, 2-6 octubre 1995).

RAMOS FERNÁNDEZ R. y RAMOS MOLINA; A. 1992: El monumento y el temenos ibéricos del Parque de Elche, Publicacions de l'Anjuntament d'Elx, Sèrie Gran, n.ำ 2, Elche. 
RAMOS SAINZ, M.L. 1986: Estudio sobre el ritual funerario en las necrópolis fenicias y púnicas de la Península Ibérica, Ediciones de la Universidad Autónoma de Madrid.

ROUILLARD, P. 1991: Les Grecs et la Péninsule Ibérique du VIIIe. au IVe. siècle avant Jésus-Christ, Publications du Centre Pierre Paris, 21, París.

SÁNCHEZ, C. 1992: El comercio de productos griegos en Andalucía oriental en los siglos VI-IV a.C.: estudio tipológico e iconográfico de la cerámica, Tesis Doctoral reproducida, Universidad Complutense de Madrid, Madrid.

SALA, F. 1995: La Contestania Ibérica entre los siglos VI y III aC. Una propuesta de evolución, Colección Textos Universitarios, Instituto de Cultura Juan Gil-Albert-Generalitat Valenciana-Universidad de Alicante.

SALA, F. y LÓPEZ, J. 1995 (e.p.): «Los Almadenes: un poblado orientalizante en la desembocadura del río Mundo (Hellín, Albacete), IV Congreso Internacional de Estudios Fenicios y Púnicos (Cádiz, 2-6 octubre 1995).

SENENT IBÁÑEZ, J.J. 1930: Excavaciones en la necrópolis del Molar, M.J.S.E.A., 107, Madrid.

VV.AA., 1991: Simposi Internacional d' Arqueologia Ibèrica. Fortificacions. La problemàtica de l'ibèric ple: segles IV-III a.C., Centre d'Estudis del Bages, Manresa. 


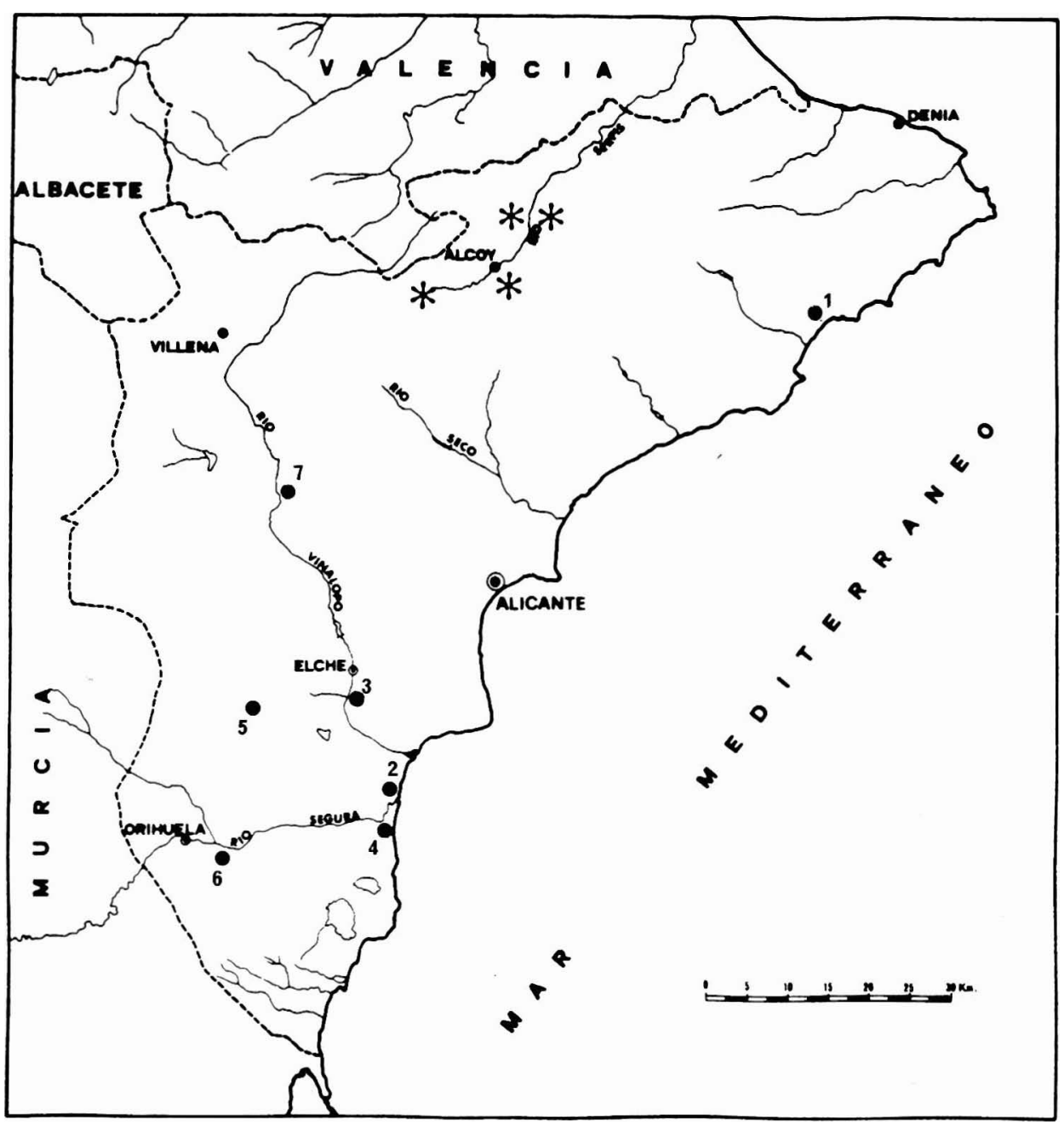

Fig. 1.- Mapa de distribución de los yacimientos citados en el texto: 1. Necrópolis y poblado de Altea la Vella; 2. El Oral y El Molar; 3. La Alcudia; 4. Factoría fenicia de Guardamar; 5. Peña Negra; 6. Saladares; 7. El Monastil. En asterisco los hallazgos de las prospecciones en el valle del Alcoià-Comtat (MARTí y MATA, 1992). 


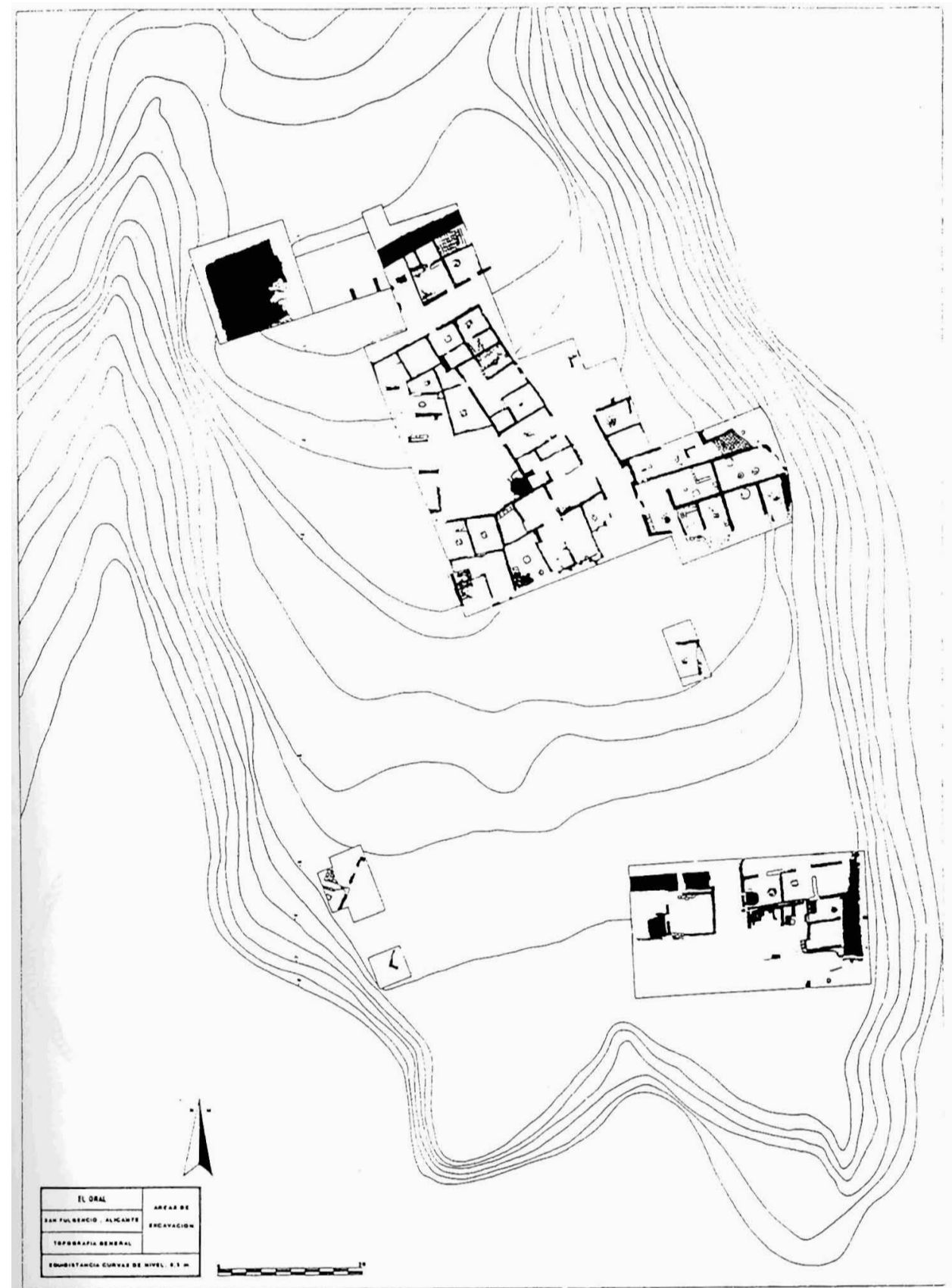

Fig. 2.- Planimetría actualizada del poblado de El Oral. 

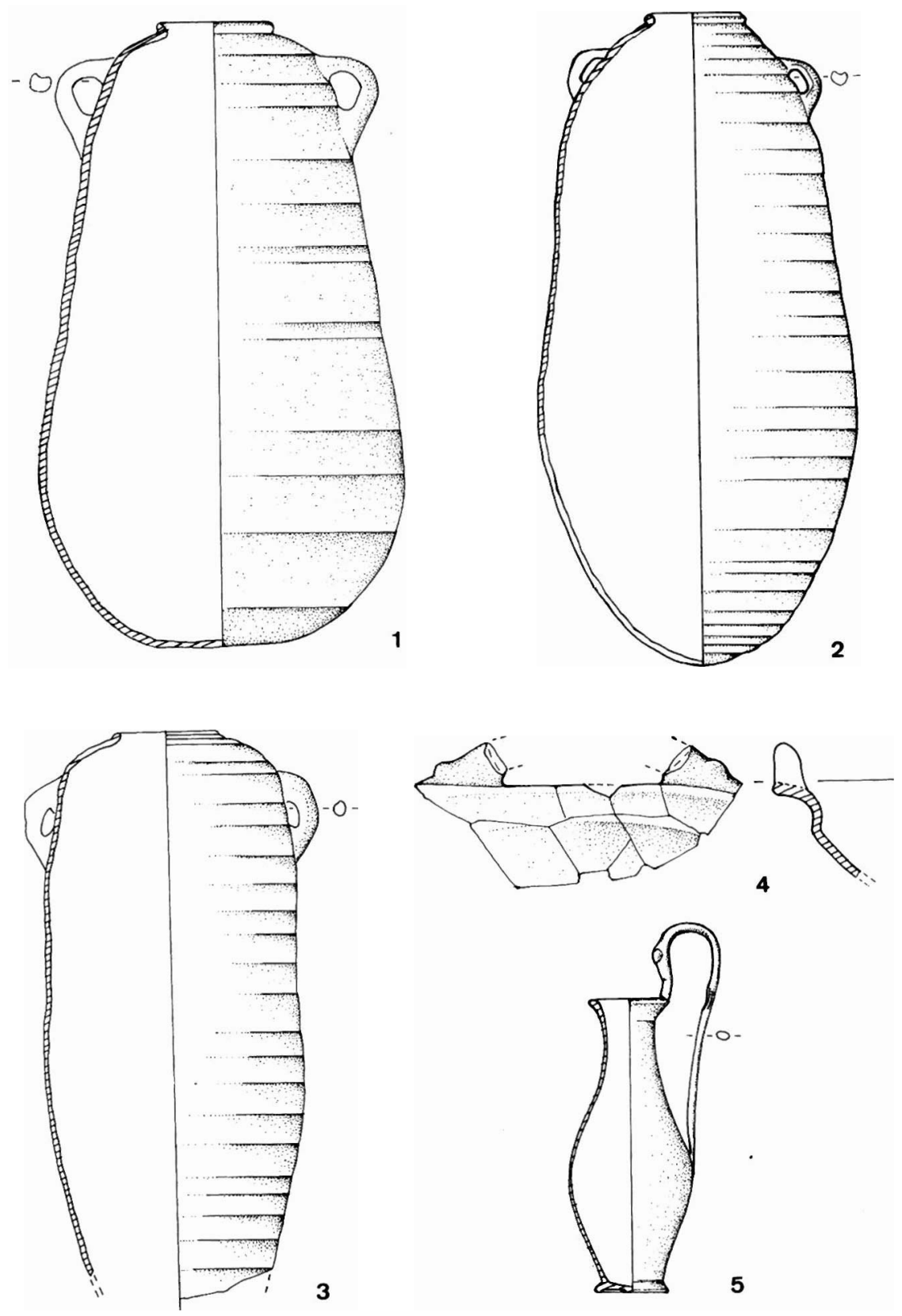

Fig. 3.- 1. Anfora de El Oral (1. ${ }^{a}$ mitad del s. V aC); 2-3. Anforas de El Puntal de Salinas (1..$^{a}$ mitad del s. IV aC); 4. Fuente de asas de espuerta de El Oral; 5 . Jarro de bronce de El Oral. A diferentes escalas: ánforas aprox. $1 / 10 ; 4$. aprox. $1 / 4 ; 5$. h. $20 \mathrm{~cm}$. 

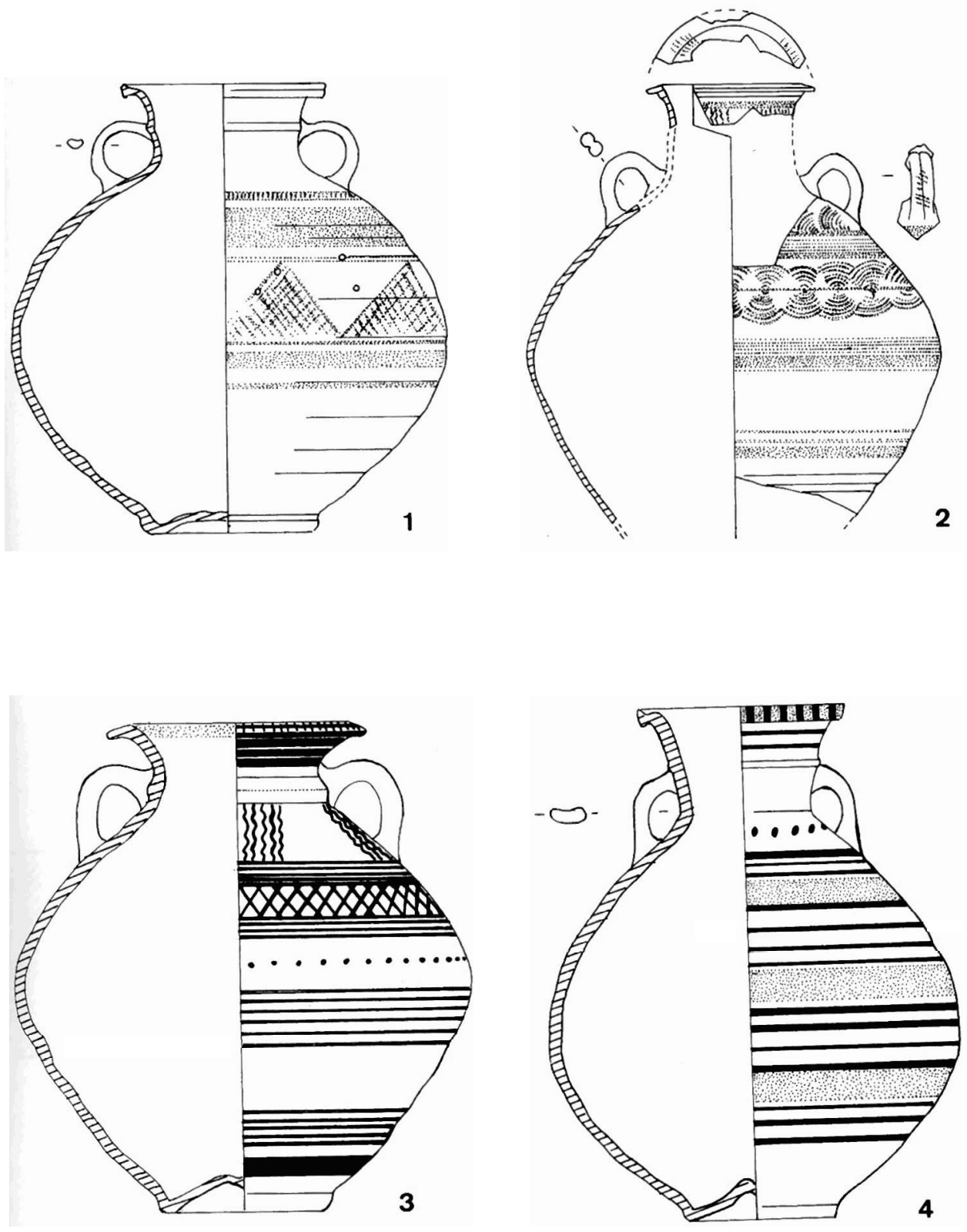

Fig. 4.- Distintas variantes de las jarras tipo Toya: 1-2. El Oral; 3. La Solivella; 4. Toya. A diferentes escalas: 1. aprox. $1 / 5 ; 2$. aprox. $1 / 8 ; 3-4$. aprox. 1/4. 

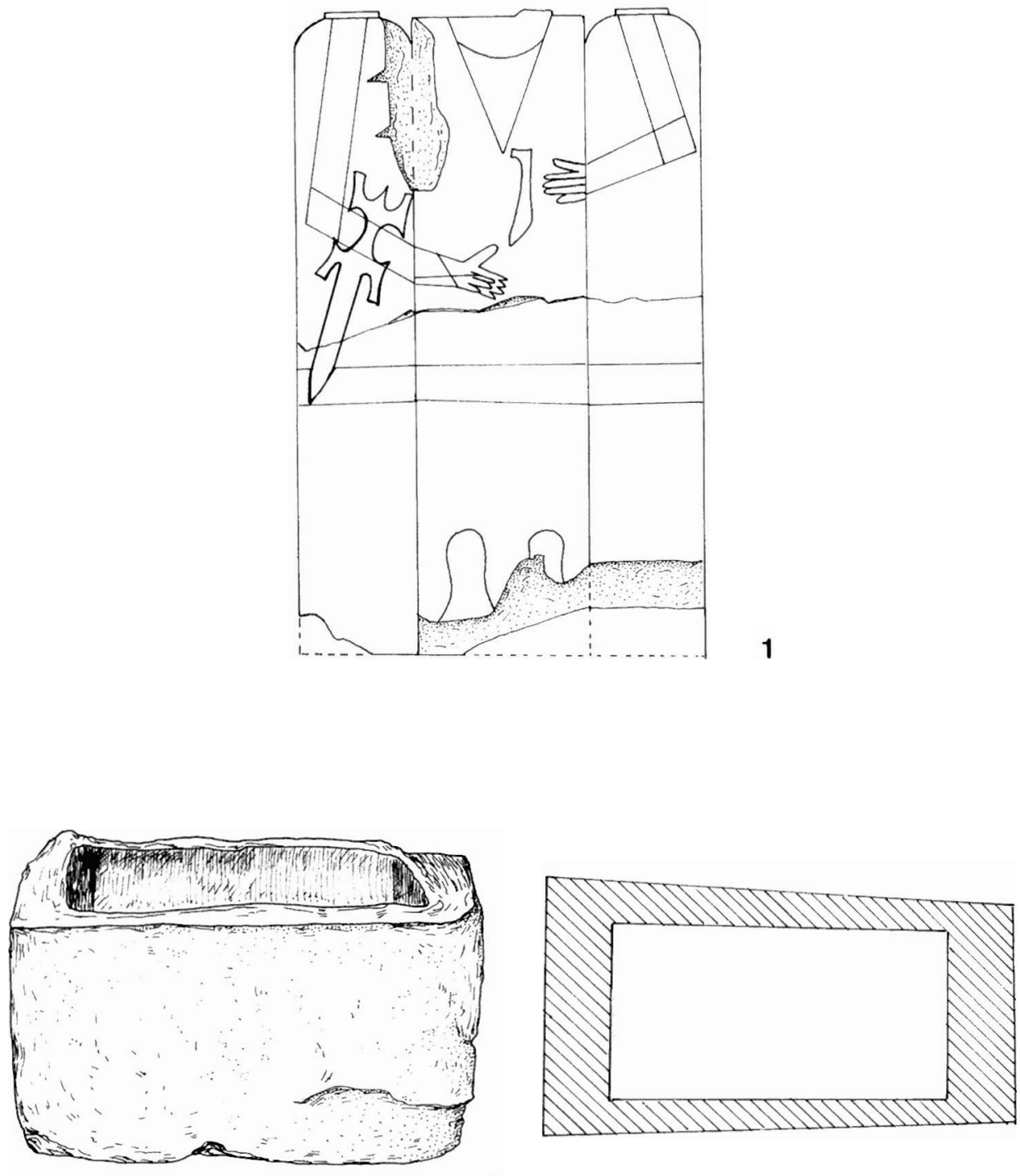

2

Fig. 5.- 1. Estela de guerrero de Altea la Vella (h. $108 \mathrm{~cm}$.); 2. Larnax de El Molar (según Monraval, 1992, 121) (long. $28 \mathrm{~cm}$.). 

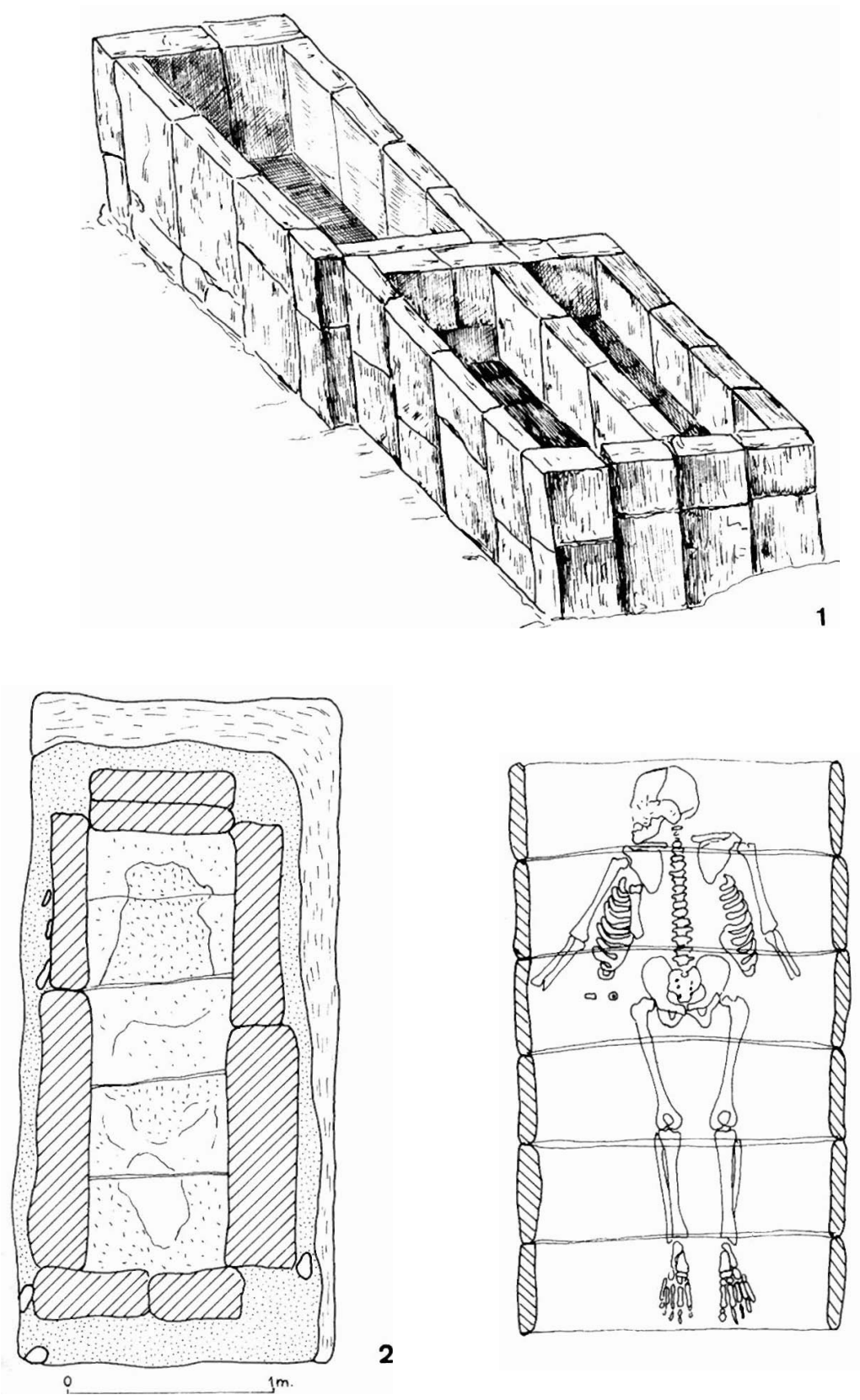

2

3

Fig. 6.- Ejemplos de enterramiento en cista: 1. Cádiz (Ramos, 1986, lám. 60); 2. Jardín (Ramos, 1986, lám. 36); 3. restitución de la inhumación en cista de El Molar, según M. Monraval (1992) a partir de la descripción de Lafuente. 